\title{
Members' Site Use Continuance on Facebook: Examining the Role of
}

\section{Relational Capital}

\author{
Rui Chen \\ Department of Information Systems and Operations Management \\ Miller College of Business \\ Ball State University \\ Muncie, IN 47396 \\ H. Raghav Rao \\ Department of Information Systems and Cyber Security \\ College of Business \\ The University of Texas at San Antonio \\ San Antonio, TX 78249 \\ Sushil K. Sharma \\ Department of Information Systems and Operations Management \\ Miller College of Business \\ Ball State University \\ Muncie, IN 47396
}




\section{Members' Site Use Continuance on Facebook: Examining the Role of Relational Capital}

\section{Abstract:}

Continued site use by social networking site (SNS) members is important to the vitality of a SNS. Through the lens of Social Capital Theory, in this paper, we theorize the potential role of relational capital in cultivating members' continued site use. We posit that relational capital in the forms of trust, community identification, and reciprocity may affect site use yet in a non-uniform manner. Specifically, we contend that community identification directly affects a member's site use continuance and that perceived member trust and perceived member reciprocity indirectly affect one's continued site use through community identification as a mediator. Drawing upon supporting literature, we further suggest likely gender differences on the effects of relational capital. Finally, we explore important antecedents to relational capital on SNS. Analysis results of survey data from Facebook members attest to many of the research hypotheses. The current study contributes to the SNS literature and also informs practice.

Keywords: Social networking site, continued site use, social capital theory, Facebook, empirical research

\section{INTRODUCTION}

Social networking sites (SNS) have mushroomed over the Internet in the recent past. SNS are online social platforms that permit users to build social relations among those who share similar backgrounds and interests. While many SNS focus on social connections (e.g., Facebook), some focus on niche areas such as multimedia sharing (e.g., Flickr), professional connections (LinkedIn), and information (e.g., Super Green Me). Popular SNS are Facebook, LinkedIn, and Pinterest. According to a recent report by Pew Internet Research, Facebook accounts for $71 \%$, LinkedIn and Pinterest each accounts for $28 \%$, and Instagram accounts for $26 \%$ of the online adults [1]. Leading the market, as of March 2016, Facebook serves 1.04 million daily active users, 934 million mobile daily active users, 1.59 billion monthly active users, and 1.44 billion mobile monthly active users.

Site use by the online population is important if a site is to survive. Studies have found site use to stop growing or enter the decline phase for major sites. Active use of Instagram and Pinterest, for example, has stopped growing while that of Twitter decreased by $10 \%$ [1]. Existing members are also constantly attracted away 
[1]. In early 2013 alone, Facebook lost nine million active monthly users in the U.S. according to social media analytics company SocialBakers [2]. It is, therefore, important for site providers to develop strategies which promote site use among their members. In this study, we follow the lens of Social Capital Theory (SCT) to develop a conceptual model that underscores important factors which affect members' continued site use. Several theoretical frameworks (e.g., Uses and Gratification Theory, Expectation Confirmation Theory, and Theory of Planned Behavior) have been extensively used in prior studies of members' continuance of SNS use [3-5]. They primarily attend to the use experience between a focal member and the information system (i.e., SNS) and capture the extent of individual outcome achievement (e.g., enjoyment). While they underscore the value of SNS as an important IT artifact in serving online users, these studies overlooked one's interaction experience with peer members for its potential role in affecting behavior. As individuals engage in SNS to interact with social contacts, their interaction experience may guide continuous site use. New findings that reveal a constructive value of member interaction experience will offer a new venue for SNS vendors to promote members' site use: they may enhance member interaction experience by strategically regulating and influencing their user communities. For example, a SNS vendor may remove fake accounts to help members avoid meeting scammers on the same platform; conceive incentive schemes to promote cooperative and reciprocal behavior; and develop loyalty programs that fortify the bonding between members and the virtual community. To capture member interaction experience, SCT provides a useful theoretical lens. It attends to the use experience between a focal member and others in the related community and it assesses the impact of online social system characteristics on individual SNS members. We discuss relational capital as "this concept focuses on aspects that influence the behaviors" [6]. Its predictive relevance also outperforms other capital, such as structural capital, in prior studies of SNS [7]. Relational capital consists of three major forms: trust, reciprocity, and community identification [8-10].

A majority of the existing SNS literature has discussed the value of site use on social capital accumulation [11-13]. Research findings that reveal the role of social capital in promoting site use are, however, scanty and not without limitations [14-16]. Early studies have, for example, failed to recognize that different forms of social capital may play varying roles in affecting members' cognition and behavior. Considering the "community" nature of SNS, we contend that community-oriented capital may act as a dominant source of influence that 
outperforms other forms of capital. Meanwhile, early studies have considered the effects of social capital on SNS users to be homogenous. Within the offline context, yet prior studies have suggested that males and females may act differently in regards to social capitals (see [17] for a review). It is reasonable to argue that gender difference may exist within the online context and continue to affect users of SNS. To fill these gaps, in this paper, we address the following research questions: (1) "How does relational capital develop on SNS?", (2) "How do the three forms of relational capital differ in cultivating member site use continuance?", and "How does gender affect the impact of relational capital on member continued site use?" We set Facebook as our research context for two reasons. First, it is by far the largest SNS in the world and it offers an ideal platform to understand SNS. Facebook has 1.59 billion monthly active users [18], which far exceeds WhatsApp (500 million), Twitter (284 million), and Instagram (200 million). Second, we are able to isolate the potential confounding effects from site-specific factors by focusing on one but not multiple SNS.

Our paper makes the following contributions. We extend the SCT literature by exploring and validating a set of important factors that impact relational capital. The paper shows that SNS member's continued site use is impacted by experience with other members. Using data gathered from Facebook members, we find community identification has a direct effect on member site use continuance, whereas perceived member trust and perceived member reciprocity impact site use continuance indirectly - their effects are mediated by community identification. Further, this study reports gender difference on the effect of social capital within the SNS context: the effect of perceived member trust on community identification is stronger among male users than among female users. The rest of the paper is organized as follows. The subsequent section introduces the theoretical foundation and reviews the related literature. Next, we present the conceptual model and discuss the set of research hypotheses. Subsequently, we discuss the research methodology and present the analysis results. We conclude the paper with theoretical contributions, practical implication, limitations, and future studies.

\section{LITERATURE REVIEW AND THEORETICAL DEVELOPMENT}

\section{Literature Review}

Prior literature has generated some insights on members' continued site use on SNS. In this section, we provide a brief review. Kim [3] employed Expectation Confirmation Theory and Theory of Reasoned Action to find out that 
perceived usefulness, perceived enjoyment, but not satisfaction affects members' continuance intention. Lankton et al. [4] adopted Theory of Reasoned Action to find trusting beliefs in SNS website and habit associate to users' intention to continue using SNS. Xu et al. [5] used Uses and Gratification Theory to find members continued site use is affected by gratifications such as immediate access, and affection. Al-Debei et al. [19] extended the Theory of Planned Behavior to find that perceived value and continuance intention jointly affect continuance behavior.

Chen and Sharma [20] borrow from the Theory of Consumption Value to find attitude affects members continued site use where attitude is shaped by member perceived values such as functional values, social values, and epistemic values. $\mathrm{Ku}$ et al. [21] utilized Uses and Gratification Theory to find that perceived gratification, privacy concern, critical mass, and subjective norm contributes to continued SNS site use. Through both Uses and Gratifications Theory and the flow literature, Huang et al. [22] found that social gratifications affect the intention to revisit SNS and that this relationship is mediated in part by interaction and arousal. Lin et al. [23] followed Bagozzi's framework of self-regulation to find satisfaction and sense of belonging affect continuance intention. Drawing upon personalization literature, Park [24] found satisfaction, personalization, and perceived switching cost affects continuance intention in SNS.

The aforementioned theoretical frameworks do not fully recognize the potential role of online virtual community in determining members' continued site use. Those frameworks largely focus on one's experience with the IT artifact (i.e., SNS as a technical solution) and individual outcome achievement (e.g., perceived usefulness, enjoyment, and switching cost). In the context of SNS, member use experience is a result of interactions that take place between a focal member and the others on a SNS, in addition to those between the focal member and the SNS system [25]. Consequently, members' use continuance may be affected by own evaluation of the virtual community on SNS. In this regard, we argue that an alternative theoretical lens with a focus on social relations will prove to be useful. In the subsequent section, we introduce Social Capital Theory (SCT) as a theoretical underpinning that helps explain SNS members' behavior, such as site use, within online social settings, along with few pioneering studies that applied SCT to study SNS.

\section{Theoretical Development}


Because SNS represents a social system where online users interact, SCT serves as an appropriate theoretical framework for us to understand members' social activities such as site use. SCT is a framework that explains individuals' pro-social behaviors within a social setting [26]. It is based on the premise that there is resource value, known as social capital, inherent in social relationships. Nahapiet and Ghoshal [10] defined social capital as "the sum of the actual and potential resources embedded within, available through, and derived from the network of relationships possessed by an individual". Social capital provides social members with "a 'credential' which "entitles them to credit" [27]. Such capital primarily roots itself within networks of mutual acquaintance and recognition and may arise from feelings of gratitude, respect, or friendship. It may also stem from contacts or connections that are brought in by social networks, including "weak ties" or "friends of friends". While other forms of capital are grounded on tangible assets such as financial resources, social capital exists "in the fabric of relationships between individuals and in individuals' connections with their communities" [9]. The central proposition of SCT is that social capital constitutes valuable resources that facilitate actions of participants within a network. When accessed and/or mobilized in purposive actions, social capital provides community members with various support, access to broader sources of information, and new opportunities [28].

In recent years, SCT has been increasingly applied to the discipline of Information Systems on broad topics such as IT innovation, IT outsourcing, software development, IT knowledge management, IT-based interorganizational linkages [29]. Yang et al. [30] suggested that social capital plays an important role in "advancing technology adoption, diffusion, and use". Existing IS studies have considered social capital both as a cause and a result of technology assisted social interactions. Where social capital is considered as a result, studies have explored the roles of information systems in building, recreation, and maintenance of social capital. In contrast, studies which have treated social capital as a cause primarily examine the effects of social capital on the development and use of ICT. For example, Wasko et al. [9] investigated how social capital influences knowledge contribution in electronic networks of practice. Chua et al. [31] studied how social capital assists in building and enacting clan control in complex IT projects.

To uncover the key motivators of SNS members' continued site use, we focus on relational capital which represents a key social capital. Relational capital describes the personal bonds that social members have 
established with one another from prior interactions [32]. This capital focuses on "actor bonds" which inspire individuals to interact with each another. Compared with other types of social capital, relational capital has a stronger influence on behaviors [6]. Furthermore, it outperforms other capital when studying SNS. Take structural capital for example. Marlow et al. [7] found that for average Facebook users, who have 120 friends, the number of users they actually communicate with is less than 10, indicating the lack of predictive validity of structural capital which concerns key issues such as network connections. A number of prior studies that explore user behavior in social systems have embraced the perspective of relational capital [14, 33-35]. Yet, the potential roles of relational capital have not been fully understood within SNS [36]. SCT literature has underscored three important relational capitals: trust, reciprocity, and community identification [8-10]. Trust has long been recognized as a crucial factor that influences end-user perceptions and behavior. In general, it is defined as the expectation that a trustee will act predictably, will fulfill his/her obligations, and will behave fairly when opportunism is likely [37]. Community identification is defined as one's own conception of self with respect to the defining features of a social group [38]. It results from one's membership in a social community , "in which the individual takes the values or standards of other individuals or groups as a comparative frame of reference" [39]. Lastly, reciprocity refers to a shared understanding on continuing relationships of exchange and it involves mutual expectations that a benefit given now will be paid in the future [40].

Some prior studies on SCT have suggested that social capital develops in collectives where a shared history, high interdependence, and closed structures are present $[10,41]$. Putnam advocated that a noteworthy level of social capital may not develop on computer-mediated communication after comparing face-to-face interactions [42]. On the other hand, recent studies suggest that SNS serves as an ideal platform to connect online users in forming social ties, both strong and weak ones. Additionally, site members accumulate social capital through their interactions with friends, colleagues, and strangers. Below we summarize findings from several key streams of pertinent research within the SNS context. First, some studies have discussed the potential of SNS in creating social capital. In the case of Facebook, Tan et al. [43] suggested that features such as status update, notification, photo sharing, tagging, commenting, poke, social profile, friends, news feed contribute to the development of social capital. Wu et al. [44] found that social relationship support mediates the relationship 
between perceived interactivity and bridging social capital. Second, research has examined the likely consequence of social capital. For instance, the sense of community improves information contribution and self-disclosure while it discourages intention to exit a social network [45]. Further, social capital in the context of SNS may generate resources and support (e.g., information and emotion) for end-users and subsequently result in better health outcomes [46].

Where site use is concerned, some SNS studies have explored the role of site use on the accumulation of social capital. For example, significant correlations have been reported between site use and social capital, which is manifested by factors such as life satisfaction and civic participation [11]. Ellison et al. [12] found associations between site use and capital that bridges, bonds, and maintain member relationships. Steinfield et al. [13] found that site use and self-esteem and satisfaction with life jointly links to social capital. Yet, for the most part, the literature is silent about the potential contribution of existing social capital in promoting SNS members to continue using a site. A few exceptions include [14-16]. These have studied different pieces of the puzzle: (1) some have studied site use intention which may not predict actual site use behavior; (2) some have developed conceptual models without empirical validation while others have employed a small sample size; (3) some have drawn research samples from members of multiple SNS platforms yet have not controlled for or mitigated the potential influence of site difference; (4) some have considered narrowly selected social capital (e.g., only "trust") when applying SCT. More importantly, these early studies haven't explored the potential differences among the three types of relational capital. SNS being an online community, it is arguable that community-oriented relational capital such as community identification may play a dominant role in promoting member site use. In contrast, the other relational capital may cast smaller effects, directly or indirectly on members' site use continuance. Finally, these studies have not explored the potential gender differences in the effects of relational capital. Gender difference has been an enduring topic for research on social capital. From the social network structure perspective and the social network resource perspective, within the offline context, the literature has argued that the two gender groups exhibit different patterns with regard to social capitals (see [17] for a review). It is likely that these offline gender differences on social capital may carry over to online interactions on SNS, where online users 
develop social capital and also become affected by it. Recent SNS studies have offered preliminary findings to highlight the gender differences of social capital [47].

We attempt to fill the research gap. Within the context of SNS, we intend to explore and validate the likely contributions of relational capital on continued member site use. Drawing upon supporting literature, we first identify the likely antecedents to the three relational capitals (trust, community identification, reciprocity) within the context of SNS. We consider the community-nature of SNS to suggest that community identification may play a major effect on member site use continuance while member trust and reciprocity may indirectly affect site use continuance. Next, we explore the underlying mechanisms through which relational capital encourages members to continue using a site. Prior studies on SNS have reported gender differences in members' perceptions and behavior $[11,45]$. In this study, we theorize the likely gender difference on the impacts of relational capital. Moreover, we control for a set of constructs that relate to site use as suggested by the existing SNS literature. Finally, our conceptual research model is empirically tested using a large research sample that is drawn from the population that uses one single SNS (Facebook).

\section{CONCEPTUAL MODEL AND HYPOTHESES}

In Figure 1, we present the conceptual research model which advocates the roles of relational capital in explaining members' site use behavior. Relational capital is argued to be shaped by various factors that stem from individual traits (e.g., trust propensity), qualities of the online community (e.g., information quality), website design (e.g., social presence), and social norms (e.g., social influence). These antecedents are informed by the supporting literature because SCT underscores the relational capital but does not prescribe its formation. Relational capital is posited to encourage members with respect to their site use behavior. The model recognizes gender as a differential factor that affects the impact of relational capital on member behavior. To isolate the unique effects of relational capital, the model also controls for the likely impacts of several relevant constructs on onsite use.

Identification is "the process whereby individuals see themselves as one with another person or group of people" [10]. In this paper, we define community identification as one's sense of belonging to a SNS community. Kramer et al. [48] found that identification with a collective leads to the concern for collective processes and outcomes. Similarly Lewicki and Bunker [49] reported that salient identification encourages the frequency of 


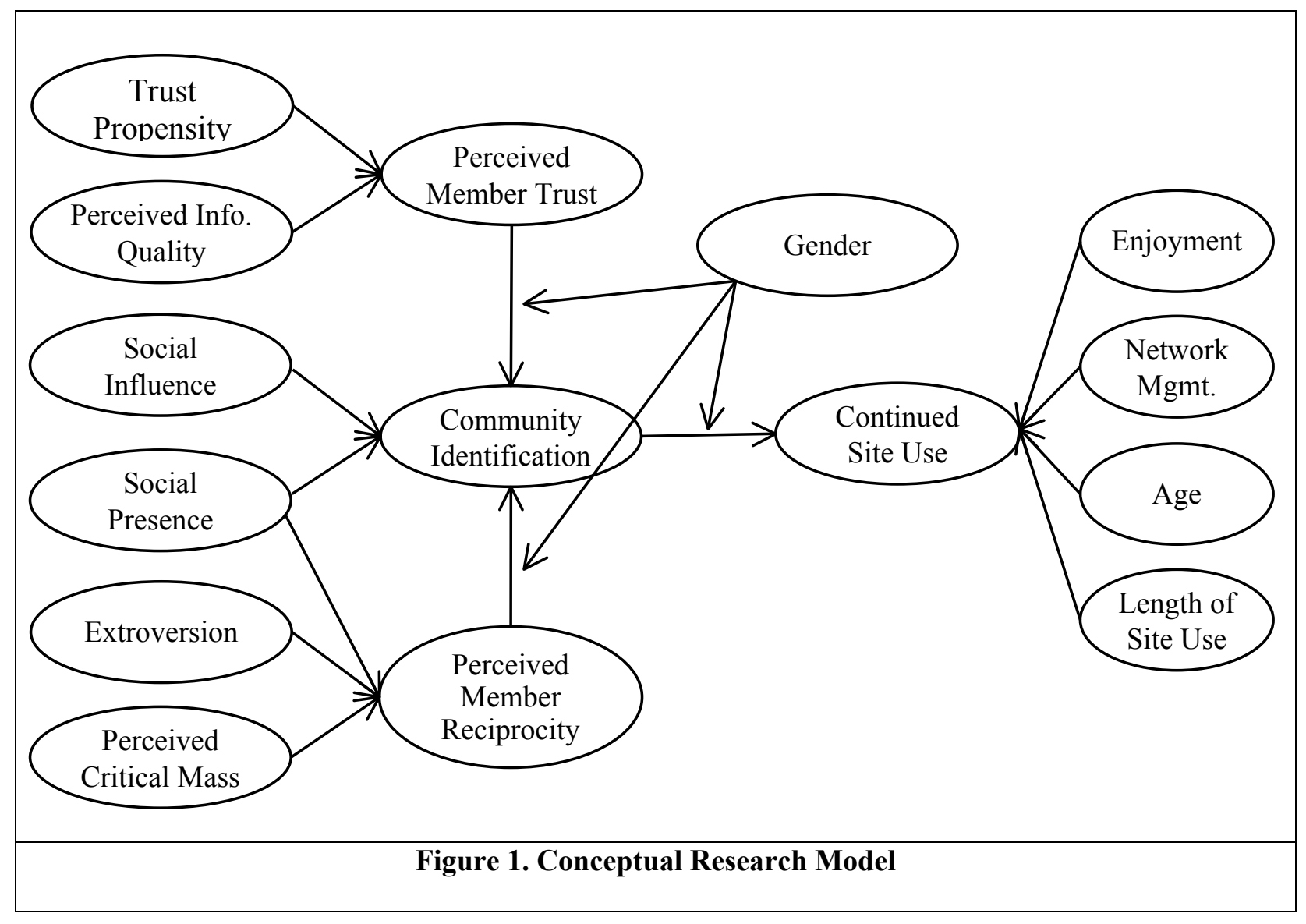

collective actions. As an Internet-enabled social platform, SNS functions on the basis of voluntary, communal interactions among site members. Frequent site use contributes to the sustainability of a SNS site in the short-run in that members engage with one another for information sharing such as status updates, conversations, mutual support such as "Likes", and ramifications such as retweets. Actions as such strengthen the existing relationships among old acquaintances while permitting the growth of new friendships. In addition, site use also opens opportunities for future site growth as a vibrant site attracts newcomers through word-of-mouth. Members' use of a SNS site, therefore, represents a citizenship behavior [50]. When one is attached to a site (i.e., strong community identification), he or she becomes motivated to contribute to the prosperity of a site through citizenship actions such as site use. A motivated member is likely to visit a site more often to add user-generated contents, participate in group activities, and interact with social contacts. Mamonov [45] found that community 
identification leads to information contribution and self-disclosure while it discourages user intention to leave Facebook. Therefore, we hypothesize that:

\section{H1: member's community identification is positively associated with continued site use.}

Trust refers to the belief that “results of somebody's intended action will be appropriate from our point of view" [51]. Trust is a psychological state that is valuable in the presence of uncertainties and adverse consequences. Within the context of SNS, one's interaction with other members can be risky due to the prevalence of cyber-attacks. Criminals can easily forge bogus accounts on SNSs by falsifying information. Subsequently, they may use these fake accounts to interact with innocent members and conduct fraudulent activities. Studies have reported that stalkers, spammers, and scammers are frequently found on SNSs and they attack unsuspected users (e.g., the distribution of malware and identity theft) [52, 53]. SNS users may suffer from consequences such as harassment, peer pressure, loss of employment, spoiled personal reputation, impaired career outlook, damaged data or networks, lost revenue or income, and burglary.

We define member trust as a member's belief that the SNS community members will behave in a manner consistent with his or her confident expectations. Members tend to use a SNS that displays high trustworthiness. It is, however, arguable that the effect of perceived member trust on continued site use is not direct. This is because members do not visit a site to find social contacts that are trustworthy; rather, they visit a site where they can fit in and develop friendship based upon common interest. Put differently, trust may not directly promote site use continuance on an online platform that is dedicated to improved social interaction. We expect perceived member trust to affect continued site use through community identification. When one has a trusting belief about the other members, he or she develops a positive view of the SNS community which cultivates the growth of personal attachment and belonging to the community. As community identification drives continued site use, perceived member trust casts an indirect effect on one's continuance behavior.

\section{H2: community identification mediates the relationship between perceived member trust and continued site use.}

Reciprocity implies "actions that are contingent on rewarding reactions from others and that cease when these expected reactions are not forthcoming" [54]. Reciprocity is enabled by the presence of mutual indebtedness between social actors who repay the benefits received from others to continue ongoing supportive 
exchange. A large body of evidence has underscored the presence of reciprocal behavior and indicates that reciprocity is a commanding determinant of human behavior [55]. Evolutionary game theory suggests that humans have evolved mental algorithms to detect and punish self-interested individuals who don't reciprocate, hence encouraging reciprocal actions [56]. Likewise, network exchange theory and social exchange theory all consider reciprocity a focal cause of individual behaviors and interpersonal relationships in a social environment $[57,58]$. Through site use, SNS members make noticeable contribution to their peers by rendering support and propagate contents that are created by others. For example, one may fave (favorite), retweet, comment, or like content shared by other members, depending on if he or she is using Flickr, Twitter, or Facebook respectively. In addition, one may choose to become a contact, follower, or friend of their peers; offer information and advice to answer questions; and engage in peer-led discussions, voting, or other group activities. Yet all these voluntary site use activities consume time and efforts. When a member believes that other community members will reciprocate in future, one will become inclined towards active site use and social interactions.

Members tend to use a SNS where members are perceived to display a high level of reciprocity. Reciprocity actions from other members allow the focal member to feel connected and supported. However, it is arguable that the effect of perceived member reciprocity on one's continued site use is indirect. This is because one does not engage in an online community such as SNS to get reciprocated - there are other platforms such as instant messaging systems that support reciprocity. Rather, they participate in a site to grow their social networks and to foster friendships with people who share similar background, interest, life style, or opinions. We contend that perceived member reciprocity affects one's continued site use through community identification.

Reciprocation signals the good will of SNS members in interacting with a focal member and, therefore, encourages one to develop a strong bonding with the community. As community identification promotes site use, perceived member reciprocity indirectly affects one's site use continuance.

H3: community identification mediates the relationship between perceived member reciprocity and continued site use.

The trust literature has underscored trust propensity as an important factor that explains individuals trusting beliefs. Trust propensity is defined as "a person's general willingness to trust others" and is "a stable 
within-party factor that will affect the likelihood that the party will trust" [59]. Trust propensity is one's tendency to be willing to depend upon others across various situations. It plays an important role when individuals engage in new relationships where uncertainty is present. Within a cyber space such as SNS, it is difficult for one to evaluate the others and develop trusting beliefs due to a lack of decision cues which are available in an offline environment (e.g., physical appearance). To this end, trust propensity serves as an important source that instills the trust that one perceives from the peers. When a member holds a stronger trust propensity, he or she will display similar patterns when assessing SNS members and subsequently have more faith in the community. On the contrary, one may view the peer members suspicious if he or she has a low propensity to believe in others in general. Therefore, we expect:

H4: trust propensity is positively associated with perceived member trust.

The extant literature on information systems has highlighted perceived information quality as an important factor that shapes user perceptions [60, 61]. Nicolaou and McKnight [62] defined perceived information quality as the cognitive beliefs about the favorable or unfavorable characteristics of the exchange information, where key information characteristics such as accuracy, completeness, and reliability. Perceived information quality is expected to facilitate the development of the trusting beliefs. Information accuracy, for example, affects the integrity aspect of interpersonal trust because individuals trust the integrity of another person who gives truthful or credible information [63]. Within the SNS context, the presence of high quality information that is shared with others suggests that community members are competent and knowledgeable about common topics. In addition, high grade information disseminated within a SNS signals the goodwill of community members in engaging each other by offering helpful content. Finally, good information indicates that members adhere to core values shared among the community, because their messages will be interpreted as unconstructive or worthless otherwise. As a consequence, sharing of high quality information tends to foster perceived trust as it acts as a positive cue that instills confidence in the members of a SNS. Therefore we propose that:

H5: perceived sharing of quality information is positively associated with perceived member trust.

Social influence is "any change which a person's relations with other people produces on his intellectual activities, emotions or actions" [64]. It refers to the psychological needs that lead one to conform to the 
expectations of a reference group. Individuals are susceptible to the influences of their referent others in selecting their behavioral choices. Kelman [65] proposed that changes to an individual's belief are made possible through processes such as compliance where one perceives the pressure to behave in the way that is approved by his or her referent others. A reference group may include family members, close friends, and coworkers who are important to an individual. Compelling messages received from important others may affect one's beliefs about an online community. When the social influence is favorable for a SNS site and is entrenched with positive beliefs that the site is esteemed, a member tends to internalize those beliefs and subsequently develops a strong belonging to the site. On the other hand, users may withdraw from a site if the site is not approved by his or her social references. H6: social influence is positively associated with community identification.

Social presence describes the subjective experience of closeness and connectedness in computer mediated interactions. It is defined as "the extent to which a medium allows users to experience others as being psychologically present" (Fulk, 1987). Social presence is embodied in the use of socially rich texts, personalized greetings, and human videos and audios, which influences the system users in developing the perception of "warm" and welcomed. A high level of social presence suggests psychological involvement and includes a sense of behavioral engagement. When online users experience social presence, they become deeply involved, absorbed, and engrossed in the relationships with the others. In addition, social presence creates the perception that other individuals display a sense of personal, sociable, and thoughtful human contact. Cyr et al. [66] confirmed that social presence in general contributes to the development of end user loyalty towards an online system. Likewise, Schimke et al. [67] observed that social presence links to group identification in a small sample of online mentor community. As a result, the presence of high social presence encourages one to value the community and subsequently develops a stronger sense of belonging. So we expect that:

H7a: perceived social presence is positively associated with community identification.

Furthermore, we expect that social presence may contribute to perceived member reciprocity. Neureiter et al. suggested that social presence may contribute to perceived reciprocity through both co-presence and mutual understanding [68]. Co-presence, for example, drives one to the belief that others will soon respond to his or her actions because those communication partners are "there." Mutual understanding as supported by a variety of 
non-verbal cues also drives one to believe that feedback collection will be convenient and timely. Song et al. added that social presence helps communications to become "more reciprocal and interactive" through the effect of perceived human warmth and psychological connection [69]. They found empirical evidence that the inclusion of social presence cues by an online store increases consumers' perceived reciprocity of the store. Extending these lines of thoughts, within the SNS context, we argue that the presence of social presence may facilitate the communication between one and peers and, subsequently, fosters the development of perceived reciprocity. H7b: perceived social presence is positively associated with perceived member reciprocity.

Extroversion is defined as a positive emotion and a tendency to seek out stimulation and the company of others [70]. Extroverts are outgoing, friendly, and socially active. Studies have shown that extroverts "tend to enjoy helping out others. They like being useful, supportive, and encouraging” [71]. Finch and Graziano [72] contended that extroverts are more attentive to their social networks' actions and needs and, therefore, make more support available to others. Likewise, Knoll et al. [73] pointed out that extroverts provide assistance as a tool to ensure social contact and stimulation. As a result, extroverts are very likely to reciprocate favors because it is consistent with their patterns of supporting the others. Martin [74] noted that "introverts are not as reciprocal in their social advances; being by nature more reserved and less outgoing, more extroverted individuals may see them as not putting as much effort into a social relationship". Heuristic theory suggests that individuals rely on their own personality characteristics in judging unfamiliar others [75-77]. That is, there exists significant correlation between an individual's self-rating on a personality and his or her assessment of another person on the same personality (e.g., between one's self-rated extroversion and own rating of others' extraversion). When compared with the others, an extrovert member tends to reciprocate more and hence perceive an online community to display a greater reciprocity as well, ceteris paribus. In contrast, introvert members who reciprocate less may expect the peers to do the same. As a result, we posit that:

H8: extroversion is positively associated with perceived member reciprocity.

Hsu and $\mathrm{Lu}$ [78] suggested that user attitude towards online systems may be affected by a perception of critical mass. Critical mass refers to the crucial point where a sufficient amount of users have adopted a technology so that the continued growth of technology use is self-sustaining [79, 80]. It is an attribute of a focal 
technology and is, therefore, conceptually different from constructs such as social influence which assesses attributes of an end user's social system. Rise and Gattiker [81] distinguished critical mass from social influence as structural processes for two reasons: "One is that critical mass theory does not usually posit a role for others' perceptions. The second is that it operates at a fundamentally different level of analysis: the network as a whole rather than individuals." End-users often resort to their subjective evaluations as to whether an information system has reached the critical mass because it is difficult to measure the actual threshold of critical mass. This perception is generally termed as perceived critical mass. When critical mass is perceived, a SNS member expects the community to secure long term vitality and prosperity by attracting more to join and take part in site activities. Within a vibrant community, the chance for reciprocity increases. First, a healthy development of a community fosters constructive communal norms and relations such as reciprocity. Second, a community that has a wealth of contributors observes a great amount of social interactions and engagements in formats such as social grooming, poking, and sharing. Third, an ever-growing social network gives rise to frequent occurrences of reciprocal behavior because of social phenomenon such as generalized reciprocity ("help anyone if helped by someone") [82]. As a result, a member will expect support from peers on a SNS site that grows well. In their studies on reciprocity, Henrich et al. $[83,84]$ noted that members in larger groups reciprocate more than small groups. H9: perceived critical mass is positively associated with perceived member reciprocity.

\subsection{Gender Differences}

Social Role Theory (SRT) is a seminal framework that explains gender differences in social activities [85]. SRT suggests that individuals' gender beliefs are derived from their observations of gender role performances. These gender role beliefs consequently shape gender behavioral differences: (1) each gender acquires specific skills and resources associated with successful role performance and (2) adapts their behavior to corresponding role requirements. In accordance with SRT, gender-differentiated behavior demonstrates communal characteristics of women and agentic characteristics of men [86]. In addition, males prefer working with things and show stronger "realistic interest" than females do [87]. Women develop communal behavior that is interpersonally facilitative, nurturing, and cooperative. To successfully develop this role, they acquire interpersonal skills and improve their nonverbal communication. Therefore, women tend to be other-oriented and compassionate. In contrast, men 
develop agentic behavior which involves patterns of independent, dominant, and competitive behavior. These traits tend to discourage males from developing friendly, sensitive, or collective behavior [88].

When joining an SNS site and developing personal bonding with the community, online users consider it as an opportunity to gain friendship. Unfortunately, members are fretful about the potential, adverse outcomes which will significantly diminish the expected utilities. Involvement in an SNS community may lead one to harassment, spoiled personal reputation, and losses to financial frauds. Perceived member trust acts as a psychological control that alleviates the perceived loss, thus sustaining the amount of utilities that a member may expect from engaging in a community. Following SRT, males are concerned about outcomes. And thus, perceived member trust may act as a salient decision factor for them in developing their community identification. This is because member trust secures positive outcomes in community engagement and, therefore, may effectively encourage males to develop a strong association with the SNS community - the source of utility. On the contrary, perceived member trust may play a less important role in affecting the site use of female users. This is because site use of female users is less motivated by the expected utilities, which can be safeguarded by perceived member trust.

H10a: the relationship between perceived member trust and community identification will be stronger among male users than among female users.

Following SRT, females are more carrying and sensitive to peers than males. Compared to males, females are more responsive to the problems of peers in their community. As a result, females may be more reciprocal towards the others as they have a greater tendency in supporting others or returning favors. Clark and Ayers [89] found that females are more reciprocal than males in managing social relationships. Given that reciprocity is the accepted social norm among them, females may deem perceived reciprocity of others as an important decision factor before they decide to bond to a community. That is, females place a high weight on whether or not a community displays values that are consistent with their own (i.e., reciprocity). Females may attach to a SNS community and subsequently develop community identification, if community peers display a great level of reciprocity; to its contrast, females may disapprove an SNS community and subsequently decline to bond to a SNS community, in case community members are believed to not reciprocate well - a violation of the accepted 
social norm valued by females. On the other hand, male members may not view received reciprocity of a community as a key consideration since they themselves do not tend to reciprocate. Therefore, we expect that: H1Ob: the relationship between perceived member reciprocity and community identification will be stronger among female users than among male users.

As SRT suggests, males are more independent and less social than females. Males report a greater level of lonesomeness than females [90]. Females, on the other hand, are more engaged in communities and offer more social support to their peers than males do [91-93]. In addition, prior studies found that males are more Machiavellian than females [94]. Displaying emotional nonchalance, high Machiavellian individuals detach from others and often decline attachment or belonging towards communities. Literature also suggested that males suppress emotions and feelings such as empathy and sympathy which are deemed as pro-social behaviors [95]. Because females easily develop community identity, the prevalence of community identity renders community identification a less differentiating factor in explaining female users' individual differences in site use. As community identification is hard to come by, it becomes a valued factor in males' decision making process and subsequently cast a strong effect. Preliminary studies have reported that identification with a community significantly predicted one's behavioral choices of involvement in organizations and such effect exists within male but not female social members [96]. The above logic implies that gender would moderate the effect of community identification on continued site use and further:

H10c: the relationship between community identification and continued site use will be stronger among male users than among female users.

In addition, we account for the potential impacts of age, website use experience (i.e., months of Facebook use), perceived enjoyment, and perceived network manageability (one's belief that a SNS helps manage personal networks) in the research model as prior studies have suggested for their potential influences on the endogenous variables in the current study [34, 97-100].

\section{RESEARCH METHODOLOGY}

We tested the research model by using empirical survey data. Survey responses were collected from 822 college students who took MBA or undergraduate courses at a large institution in the Midwestern United States. College 
students are a significant segment of social networking site users. A recent Quintly analysis showed 18 to 24 year-olds presented the largest user group on Facebook [101]. Therefore, the student sample is appropriate for the current research. Recent SNS studies have also considered students [19, 23, 102, 103]. The research subjects consisted of business and non-business major students; the sample is therefore heterogeneous. Respondents were guaranteed both confidentiality and access to the aggregated survey results. Participation in the survey was voluntary. Table 1 provides the descriptions of respondent demographic information. The survey measurement items were developed by borrowing from the existing literature. Detailed measurements of the key constructs and their sources are presented in Appendix A. All items were measured on a 1-7 point Likert scale. The survey instruments were pretested with 60 users of a social networking site to check the psychometric properties of the measurement scales. Following this pretest, the measurement instruments were improved. We replaced "my social networking site" to "this social networking site" and we removed the wording of "knowledge" in the measurement of perceived information quality to avoid any confusion between the concepts of knowledge and information."

\begin{tabular}{|l|l|}
\hline \multicolumn{2}{|c|}{ Table 1. Demographic Information } \\
\hline Gender & 475 male and 347 female \\
\hline Age & 20.5 on average; range of 17-56 \\
\hline Year of experience in computer usage & 10.7 \\
\hline Year of experience in Internet usage & 9.74 \\
\hline Months of use experience in Facebook & 43.3 \\
\hline Student major & About $60 \%$ in business and $40 \%$ in other majors \\
\hline
\end{tabular}

\section{ANALYSIS AND RESULTS}

We tested the research model using partial least squares (PLS). PLS offers a wide range of benefits: (1) suitability to exploratory research where relationships have not been fully examined, (2) tolerance of possible violations of multivariate normality and use of non-interval scaled data, (3) avoidance of parameters estimation biases, and (4) independence of parameter estimation from sample size [104]. Our paper investigates members' continued SNS use through the lens of SCT as well as the major antecedents to SCT constructs, which has received limited validation in the current research context. Further, PLS is useful with multiple dependent variables and when one dependent variable becomes an independent variable. PLS is, therefore, appropriate for the current study. 


\subsection{Measurement Model}

Table 2 reports the correlation matrix, the AVEs, and the descriptive statistics of the principal constructs.

Measurement reliability was assessed using composite reliability and Cronbach's alpha. Fornell and Larcker [105] suggested a composite reliability of .70 or greater is considered acceptable for research. Nunnally [106, 107] suggested a Cronbach's alpha of .70 or greater is considered acceptable. As in Table 2, the internal consistencies of all variables are considered acceptable, thus signifying satisfactory reliability.

\begin{tabular}{|c|c|c|c|c|c|c|c|c|c|c|c|c|c|c|c|c|c|c|c|}
\hline & Research Constructs & Mean & Std & CR & $\mathrm{CA}$ & 1 & 2 & 3 & 4 & 5 & 6 & 7 & .43 & 9 & 10 & 11 & 12 & 13 & 14 \\
\hline 1 & $\begin{array}{l}\text { Community } \\
\text { Identification }\end{array}$ & 3.77 & 1.33 & .93 & .88 & .90 & & & & & & & & & & & & & \\
\hline 2 & Enjoyment & 5.03 & 1.15 & .94 & .91 & .53 & .86 & & & & & & & & & & & & \\
\hline 3 & Extroversion & 5.48 & 1.12 & .88 & .80 & .17 & .24 & .84 & & & & & & & & & & & \\
\hline 4 & Information Quality & 3.86 & 1.26 & .94 & .90 & .44 & .35 & .14 & .91 & & & & & & & & & & \\
\hline 5 & Length of Site Use & 43.3 & 22.3 & 1.0 & 1.0 & .04 & .09 & .06 & -.02 & 1.0 & & & & & & & & & \\
\hline 6 & $\begin{array}{c}\text { Perceived Network } \\
\text { Manageability }\end{array}$ & 5.82 & 1.1 & .91 & .87 & .31 & .52 & .29 & .22 & .12 & .85 & & & & & & & & \\
\hline 7 & $\begin{array}{c}\text { Perceived Critical } \\
\text { Mass }\end{array}$ & 6.41 & 0.97 & .94 & .90 & .05 & .21 & .15 & -.02 & .14 & .42 & .91 & & & & & & & \\
\hline 8 & $\begin{array}{c}\text { Perceived Member } \\
\text { Trust }\end{array}$ & 2.96 & 1.28 & .94 & .92 & .42 & .24 & .01 & .43 & -.05 & .04 & -.09 & .89 & & & & & & \\
\hline 9 & $\begin{array}{c}\text { Perceived Member } \\
\text { Reciprocity }\end{array}$ & 4.72 & 1.19 & .95 & .93 & .41 & .44 & .19 & .30 & .04 & .39 & .22 & .19 & .91 & & & & & \\
\hline 10 & Social Influence & 4.61 & 1.34 & .96 & .94 & .39 & .27 & .09 & .19 & -.01 & .32 & .23 & .14 & .30 & .94 & & & & \\
\hline 11 & Social Presence & 4.65 & 1.32 & .90 & .83 & .48 & .44 & .16 & .33 & .02 & .42 & .18 & .21 & .35 & .30 & .86 & & & \\
\hline 12 & Trust Propensity & 4.09 & 1.22 & .92 & .89 & .20 & .18 & .17 & .23 & .03 & .13 & .02 & .30 & .22 & .12 & .15 & .87 & & \\
\hline 13 & Continued Site Use & 5.36 & 1.65 & .96 & .94 & .39 & .47 & .14 & .14 & .11 & .38 & .28 & .05 & .27 & .26 & .21 & .13 & .95 & \\
\hline 14 & Age & 20.5 & 3.5 & 1.0 & 1.0 & -.01 & -.04 & $\mid-.10$ & .02 & .09 & -.05 & -.05 & .01 & .05 & -.06 & .02 & .07 & -.09 & 1.0 \\
\hline
\end{tabular}

Convergent and discriminant validity are inferred when (1) the square root of each construct is larger than its correlations with the other constructs; (2) all AVEs are greater than .50; and (3) the PLS indicators load much 
higher on their hypothesized construct than on other constructs [108]. As shown in Table 2, the square roots of the AVE are all greater than 0.5 and greater than all other cross correlations, indicating the variance explained by each construct is much larger than the measurement error variance. As in Appendix B, all items load high on their own constructs. These tests validate the measurement properties of principal constructs.

The research data was collected from a single survey; therefore, we checked for the extent of common method bias. First, the Harman's one-factor test was performed by including all the variables in a principal components factor analysis [109]. Common method bias exists when one single factor emerges or when one factor accounts for the majority of the covariance among the variables. The results showed that none of the emergent factors explained the majority of the covariance. Second, the correlation matrix was examined for highly correlated factors. The common method bias exists when there exist extremely high correlations ( $r>9$ ). Table 2 does not reveal such evidence. Finally, we followed the confirmatory method by including in the PLS model a common method factor whose indicators comprise of all the principal construct's indicators. According to Williams et al. [110], evidence of common method bias is obtained by a comparison between the variances of each observed indicator explained by its substantive construct and by the method factor. Besides, common method bias can be detected by inspecting the statistical significance of factor loadings of the method factor. We performed the analysis following $[111,112]$. The analysis results show that the average substantively explained variance of the indicators is 0.803 whereas the average method based variance is 0.001 . The ratio of substantive variance to method variance is 803 (calculated as $803=.803 / 0.001$ ) which is substantially large. All but three method factor loadings were insignificant. Common method bias is therefore an unlikely threat for this study.

\subsection{Structural Model}

Regarding the control variables, perceived enjoyment $(b=.29, p<.001)$, perceived network manageability $(b=.16$, $\mathrm{p}<.001)$, age $(\mathrm{b}=-.07, \mathrm{p}<.05)$, and length of site use $(\mathrm{b}=.07, \mathrm{p}<.05)$ were found to significantly associate to continued site use. An overall review of the PLS analysis results is displayed in Figure 2. In addition, we used Stone-Geisser's $Q^{2}$ to assess the predictive relevance and $Q^{2}$ was calculated by using the blindfolding procedure $[113,114]$. In this research model, we calculated $Q^{2}$ for endogenous constructs as: continued site use $(0.25)$, perceived member trust (0.18), community identification (0.32), and perceived reciprocity $(0.14)$. All $Q^{2}$ values 
were greater than zero which indicates that the structural model has sufficient predictive power [115]. The average $Q^{2}$ value is 0.23 , suggesting an overall, medium predictive relevance for the endogenous constructs. Moreover, we computed the Goodness of Fit (GoF) to access the overall quality of the research model. Though PLS doesn't offer overall fit statistics, scholars have started to calculate GoF [116]. GoF is the geometric mean of the average communality and the average $\mathrm{R}^{2}$. The GoF of the current research model was calculated as 0.47 , exceeding the .36 cutoff value for a large $\mathrm{R}^{2}$ effect. We also tested if our research design and analysis carried adequate power to find the significant relationships for all the dependent variables in this study. Applying the power analysis method for multiple regression suggested by Cohen [117] and Cohen, Cohen, West and Aiken [118], we found calculated powers of all the dependent variables are greater than 0.9.

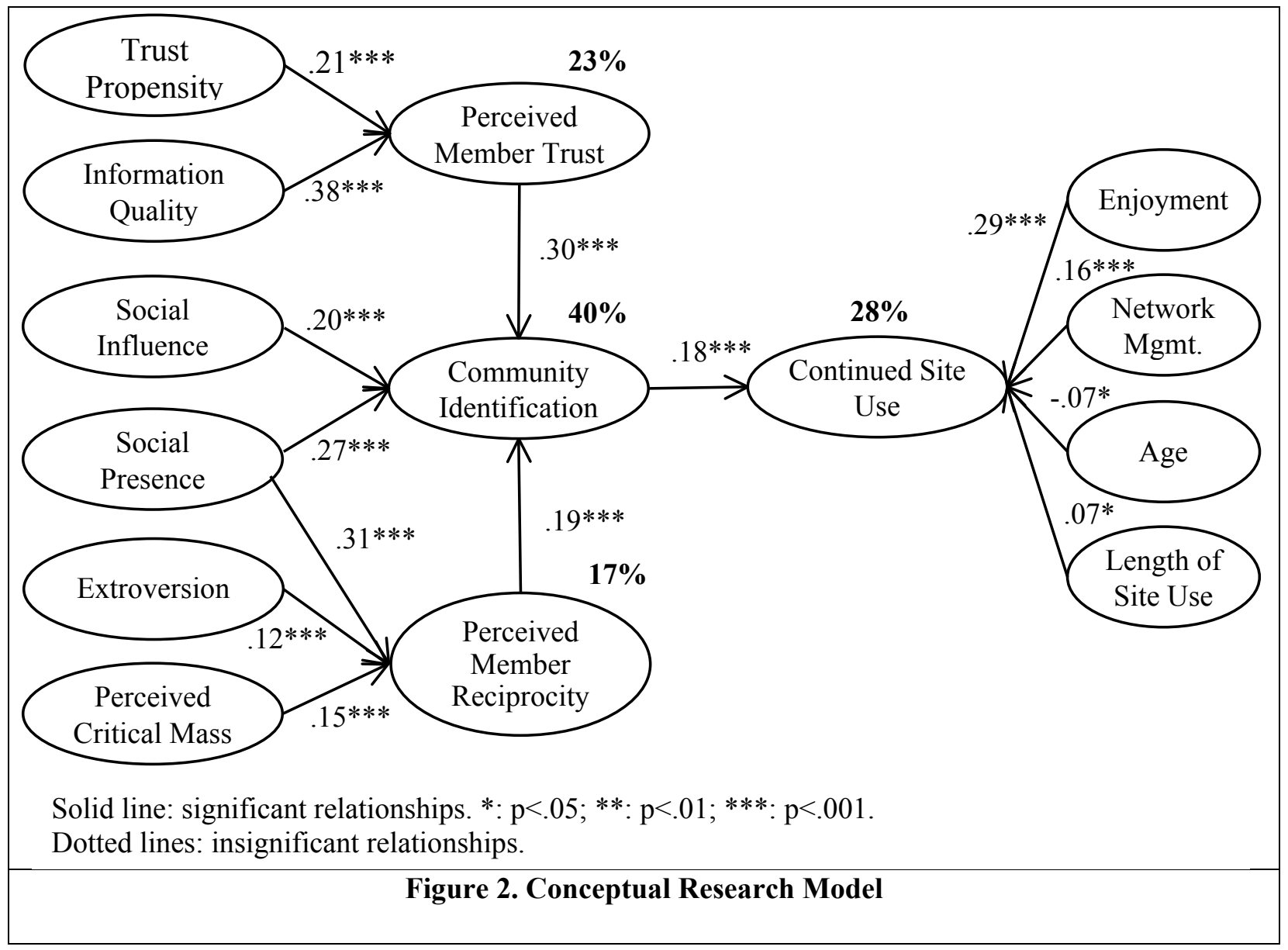

Recent advancements in statistical analysis have questioned the use of Baron and Kenny approaches as well as the Sobel test $[119,120]$. Zhao et al. [121], Hayes [122], and MacKinnon and Fairchild [123] summarized 
the limitations of the existing method as: (1) there need not be a significant predictor - predicted variable link (the zero-order effect) in a proper mediation analysis; (2) there need not be partial effect of mediator in the equation predictor - predicted variable by predictor and mediator; (3) the outcome of "partial" rather than "full" mediation can be a positive rather than a negative; and (4) the power of the Sobel test is much lower compared with new bootstrap tests in testing the mediation effects. We used Preacher et al.'s procedure and computed bias-corrected bootstrap confidence intervals [120]. According to MacKinnon et al. [124], this method has been shown to constitute a more valid and powerful method for assessing indirect effects. Using Hayes' (2013) SPSS macro, we ran regression equations and estimated the mediator variable models, enabling us to estimate indirect effects by bootstrapping methods (5,000 bootstraps). If the bootstrapped $95 \%$ confidence interval of indirect effects does not include 0 , the indirect effect is found significant and mediation is supported [121]. Table 3 summarizes the results of the mediation tests. Using 5,000 bootstraps samples for bias corrected bootstrap, the $95 \%$ confidence interval of the indirect effect of perceived member trust on continued site use is $[0.1760,0.2884]$ and the $95 \%$ confidence interval of the indirect effect of perceived member reciprocity on continued site use is $[0.1250,0.2284]$. Therefore, $\mathrm{H} 2$ and $\mathrm{H} 3$ were both supported.

\section{Table 3. Mediation Test Results}

\begin{tabular}{|l|c|c|c|c|}
\hline \multicolumn{1}{|c|}{ Indirect Effects through Community Identification } & Confidence Interval & Boot & SE & Mediation \\
\hline Perceived Member Trust $\rightarrow$ Continued Site Use & {$[0.1760,0.2884]$} & .2282 & .0287 & Yes \\
\hline Perceived Member Reciprocity $\rightarrow$ Continued Site Use & {$[0.1250,0.2284]$} & .1742 & .0267 & Yes \\
\hline
\end{tabular}

To test the gender difference, we followed Chin's multi-group analysis approach to test the significance of path coefficient differences across male and female groups [125].

$$
t=\frac{\text { Path }_{\text {sample_1 }_{1}}-\text { Path }_{\text {sample_2 }_{2}}}{\left[\sqrt{\frac{(m-1)^{2}}{(m+n-2)} * S \cdot E_{\text {sample } 1_{1}^{2}}^{2}+\frac{(n-1)^{2}}{(m+n-2)} * S \cdot E_{\text {sample } 2_{2}^{2}}^{2}}\right] *\left[\sqrt{\frac{1}{m}+\frac{1}{n}}\right]}
$$

Table 4 shows the relationships for the two SNS member groups. T test statistics showed significant between-group difference on the relationship between perceived member trust and community identification $(\mathrm{t}=$ 
2.333, $\mathrm{p}<.02$ ). The relationship strength is stronger in the male user group than in the female user group, confirming H10a. However, H10b and H10c were not confirmed.

\begin{tabular}{|l|c|c|c|}
\hline \multicolumn{3}{|c|}{ Table 4. Model Validation between Male and Female Facebook Users } \\
\hline Relationships & Female (347) & Male (475) & Difference \\
\hline Perceived Member Trust $\rightarrow$ Community Identification & .22 & .35 & $-.13^{* *}$ \\
\hline Perceived Member Reciprocity $\rightarrow$ Community Identification & .22 & .17 & .05 \\
\hline Community Identification $\rightarrow$ Continued Site Use & .15 & .21 & -.06 \\
\hline$*: p<.05 ; * *: p<.02 ; * * *: p<.001$ & & & \\
\hline
\end{tabular}

We also performed a post-hoc analysis to determine if there exists any gender difference in the mediation effect of community identification. We followed the same Hayes' (2013) SPSS macro approach as detailed above. For males SNS members, the $95 \%$ confidence intervals of the indirect effect of perceived member trust on continued site use and that of perceived member reciprocity on continued site use are $[.2137, .3797]$ and $[.1187, .2547]$, respectively. For females: these indirect effects are $[.1005, .2511]$ and $[.0813, .2460]$, respectively. These findings show that mediation effects are robust as they exist in both gender groups.

\section{CONCLUSION}

Our paper makes the following contributions. First, it contributes to the SNS literature by attesting to the importance of relational capital in explaining member site use behavior. In this study we argue that a members' actions may be impacted by their own experience with other members and we contend that characteristics of virtual SNS community may affect one's site use continuance. We adopt SCT as the underlying theoretical lens. We theorize a direct connection between community identification and members' continued site use and also argue for the indirect effects of perceived member trust and perceived member reciprocity on site use continuance. Using data collected from Facebook members, we find support that relational capital in the form of community identification serves as a major decision factor in promoting a member's site use behavior. Adding to the SCT literature, we are the first to confirm that community identification mediates the effects of perceived trust and perceived reciprocity on members' site use continuance. Second, this paper contributes to the SNS literature by 
revealing a set of precursors that cultivate the development of relational capital. As SCT by itself does not posit the antecedents to social capital, researchers need to search for those relevant antecedents within specific research contexts. Drawing upon the supporting literature, within the SNS context, we identify several factors that may foster the growth of relational capital. While their effects on other research constructs have been explored in studies outside the SNS context, the specific effects of these antecedents on relational capital remain largely unknown. Empirical analysis using data from Facebook members attest to the importance of these factors. Third, this study contributes to the SNS studies by revealing important gender differences. Following SRT, we contend that the effects of relational capital vary between male and female SNS member, due to differences in interaction styles, outcome expectations, and personality between the two gender groups. Statistical analysis results confirm that the relationship between perceived member trust and community identification is stronger among male users than among female users. To the best of our knowledge, we are the first to investigate and report this gender difference on relational capital within the SNS context.

Our study informs both SNS users and vendors. When users are concerned, members' continued site use may lead to interpersonal interactions (e.g., reading and commenting on personal updates) and generate valuable user generate content for personal learning (e.g., inspiring remarks or insightful travel journals) or enjoyment (e.g., pictures of a joyful birthday party). As a result, existing members benefit from continued site use of their peers. When peers reduce or stop their SNS use, the gratification utility that one may derive shrinks. As the empirical results show, one may encourage peers' site use continuance through a number of options. For example, one may reciprocate more so as to increase perceived member reciprocity that is held by peers. As perception of member reciprocity indirectly boosts continued site use, peers who perceive an increase in member reciprocity are likely to intensify their site use. Likewise, one may behave in a more trustworthy manner (e.g., providing quality information and not taking advantages of others) to increase the perception of member trust that is held by their peers. Considering the indirect effect of perceived member trust on site use continuance, one's action as such will encourage their peers to use the site more often. Regarding SNS vendors, our results offer strategies that promote site use. Community identification, for example, directly increases members' continued site use. As community identification is affected by social presence, vendors may improve the support of social presence through 
inclusion of more human contacts such as icons, pictures, and videos, which offer personal touch to an online, virtual system such as SNS. Since community identification is supported by positively social influence, a SNS vendor may also employ media campaigns to foster a positive brand image among the general public, including those reference groups and important opinion leaders. Moreover, SNS vendors may improve members' community identification by altering members' perceptions of peers' trust and reciprocity. To do so, vendors may either employ incentives that promote appropriate acts (e.g., schemes that reward or recognize reciprocal behaviors), punitive tactics that penalize undesirable acts (e.g., permitting users to report deceptive behaviors through the use of "Report" button), or both.

Our study is not without limitations. First, the current study employs college students as the research sample. Recent SNS studies have considered students [19, 23, 102, 103] as an appropriate research sample. While this population represents an important user segment of Facebook, our results must be treated with caution in terms of its generalizability to other user populations of social networking sites. Indeed, there exist many social networking sites which can be accessed by people in different age groups. Therefore, future research may extend the research scope to include people in different age groups. Yet this does not diminish the value of the current research as it provides a foundation for future investigations that may follow. For example, one may contrast young adults and other age groups to find out whether the effect of relational capital on site use continuance remain stable. There is even a possibility for a longitudinal study that explores whether or not the drivers of site use continuance change as members move from one age group to another. Second, the current study employs a cross-sectional design and, therefore, causality cannot be inferred. While a longitudinal analysis is preferred, cross-sectional models must first be established before future research can examine their viability over time [126]. Third, the current study utilizes self-reported survey data to assess online use behavior following [127, 128]. Prior studies have found a positive correlation between self-reported and actual data of members' use of Facebook [129]. Nevertheless, future studies may use direct questions about use times (e.g., ten times per day) to capture actual site use. Fourth, future studies may employ site-specific features and examine their impacts on members' continuous site use. To increase the variance of those constructs, it requires a different research design where data is collected from members of multiple SNS platforms. Additionally, future study may consider more personality 
types and investigate their potential effects on members' continued site use. Finally, new studies may explore other antecedents to perceived reciprocity.

\section{REFERENCES}

[1] PewResearch, Social Media Update 2014, Pew Research Center, 2015.

[2] V. Woollaston, Facebook Users Are Committing 'Virtual Identity Suicide' in Droves and Quitting the Site Over Privacy and Addiction Fears, DailyMail.com, London, UK, 2013.

[3] B. Kim, Uderstanding Antecedents of Continuance Intention in Social-Networking Services, Cyberpsychology, Behavior, and Social Networking, 14 (2011) 199-205.

[4] N.K. Lankton, D.H. McKnight, J.B. Thatcher, The Moderating Effects of Privacy Restrictiveness and Experience on Trusting Beliefs and Habit: An Empirical Test of Intention to Continue Using a Social Networking Website, Engineering Management, IEEE Transactions on, 59 (2012) 654-665.

[5] C. Xu, S. Ryan, V. Prybutok, C. Wen, It is not for fun: An examination of social network site usage, Information \& Management, 49 (2012) 210-217.

[6] J. Macke, E.K. Dilly, Social Captial Dimensions in Collaborative Networks: The Role of Linking Social Capital, International Journal of Social Inquiry, 3 (2010) 121-136.

[7] C. Marlow, L. Byron, T. Lento, I. Rosenn, Maintained Relationships on Facebook, 2009.

[8] C.M. Chiu, M.H. Hsu, E.T.G. Wang, Understanding Knowledge Sharing in Virtual Communities: An Integration of Social Capital and Social Cognitive Theories, Decision Support Systems, 42 (2006) 1872-1888. [9] M.M. Wasko, S. Faraj, Why Should I Share? Examining Social Capital and Knowledge Contribution in Electronic Networks of Practice, MIS Quarterly, 29 (2005) 35-57.

[10] J. Nahapiet, S. Ghoshal, Social capital, intellectual capital, and organizational advantage, Academy of Management Review, 23 (1998) 242-267.

[11] S. Valenzuela, N. Park, K.F. Kee, Is There Social Capital in a Social Network Site?, Journal of Computer Mediated Communication, 14 (2009) 875-901.

[12] N.B. Ellison, C. Steinfeld, C. Lampe, The Benefits of Facebook "Friends:" Social Capital and College Students' Use of Online Social Network Sites, Journal of Computer Mediated Communication, 12 (2007).

[13] C. Steinfeld, N. Ellison, C. Lampe, Social Capital, Self-Esteem, and Use of Online Social Network Sites: A Longitudinal Analysis, Journal of Applied Development Psychology, 29 (2008) 434-445.

[14] T. Hu, W.J. Kettinger, Why People Continue to Use Social Networking Services: Developing a Comprehensive Model, International Conference on Information Systems, Montreal, Canada, 2008.

[15] Y. Pan, X. Chen, C. Cai, Y. Dong, Understanding Social Network Sites Continuance Intention from a SelfDisclosure and Social Capital Perspective, the 18th Pacific Asia Conference on Information Systems, Chengdu, China, 2014. 
[16] S. Musembwa, S. Paul, Social Networks: Cultural Diversity, Trust, Reciprocity and Social Capital, the Americas Conference on Information Systems, 2012.

[17] S.M. Kim, M. Sherraden, The Impact of Gender and Social Networks on Microenterprise Business Performance, Journal of Sociology \& Social Welfare, XLI (2014) 49-69.

[18] Facebook, Company Info, Facebook.com, Menlo Park, CA, 2016.

[19] M.M. Al-Debei, E. Al-Lozi, A. Papazafeiropoulou, Why people keep coming back to Facebook, Decision Support Systems, 55 (2013) 43-54.

[20] R. Chen, S.K. Sharma, Understanding Member Use of Social Networking Sites: A Value Analysis, Communications of the Association for Information Systems, 33 (2013) 97-114.

[21] Y.C. Ku, R. Chen, H. Zhang, Why Do Users Continue Using Social Networking Sites? An Exploratory Study of Members in the United States and Taiwan, Information \& Management, 50 (2013) 571-581.

[22] L.-Y. Huang, Y.-J. Hsieh, Y.-C.J. Wu, Gratifications and social network service usage: The mediating role of online experience, Information \& Management, 51 (2014) 774-782.

[23] H. Lin, W. Fan, P.Y.K. Chau, Determinants of users' continuance of social networking sites: A selfregulation perspective, Information \& Management, 51 (2014) 595-603.

[24] J.-H. Park, The effects of personalization on user continuance in social networking sites, Information Processing \& Management, 50 (2014) 462-475.

[25] B. Han, An Investigation of Factors Influencing the User's Social Network Site Continuance Intention, University of North Texas, Denton, TX, 2012.

[26] P.S. Adler, S.W. Kwon, Social Capital: Prospects for a New Concept, Academy of Management Review, 27 (2002) 17-40.

[27] P. Bourdieu, The Forms of Capital, in: J.G. Richardson (Ed.) Handbook of Theory and Research for the Sociology of Education, Greenwald Press, New York, NY, 1986, pp. 241-255.

[28] N. Lin, Social Capital, Cambridge University Press, Cambridge, UK, 2001.

[29] V. Balijepally, R. Mahapatra, S.P. Nerur, Social Capital: A Theorical Lens for IS Research, Americas Conference on Information Systems, 2004.

[30] S. Yang, H. Lee, S. Kurnia, Social Capital in Information and Communication Technology Research: Past, Present, and Future, Communications of the Association for Information Systems, 25 (2009).

[31] C.E.H. Chua, W.K. Lim, C. Soh, S.K. Sia, Enacting Clan Control in Complex IT Projects: A Social Capital Perspective, MIS Quarterly, 36 (2012) 577-600.

[32] M.S. Granovetter, Problems of Explanation in Economic Sociology, in: N. Nohria, R.G. Eccles (Eds.)

Networks and Organizations: Structure, Form, and Action, Harvard Business School Press, Boston, MA, 1992.

[33] A. Kankanhalli, B.C.Y. Tan, K.K. Wei, Contributing Knowledge to Electronic Knowledge Repositories: An Empirical Investigation, MIS Quarterly, 29 (2005) 113-143. 
[34] B. Phillips, B. Shipps, Frequency of Usage: The Impacts of Technology Acceptance Factor versus Social Factors, Americas Conference on Information Systems, Detroit, MI, 2011.

[35] S. Chai, S. Das, H.R. Rao, An Exploratory Study of Bloggers' Information Sharing Behavior: The Role of Online Privacy Concerns, Americas Conference on Information Systems, 2008.

[36] N. Boer, H. Berends, The relational Dimension of Knowledge Sharing, 4th European Conference on Organizational Knowledge, Learning and Capabilities, Barcelona, Spain, 2003.

[37] A. Zaheer, B. McEvily, V. Perrone, Dose Trust Matter?, Organization Science, 9 (1998) 141-159.

[38] R.P. Bagozzi, U.M. Dholakia, Intentional Social Actions in Virtual Communities, Journal of Interactive Marketing, 16 (2002) 2-21.

[39] R.K. Merton, Social Theory and Social Structure, Free Press, New York, 1968.

[40] R.D. Putnam, The Prosperous Community, The American Prospect, 4 (1993) 35-42.

[41] N. Nohria, R.G. Eccles, Face-to-Face Making Network Organizations Work, in: N. Nohria, R.G. Eccles (Eds.) Networks and Organizations, Harvard Business School Press, Boston, MA, 1992, pp. 288-308.

[42] R.D. Putnam, Bowling Alone - The Collapse and Revival of American Community, Simon \& Schuster, New York, 2000.

[43] W.K. Tan, T.T.D. Nguyen, K.K.O. Tha, X.H. Yu, Designing Groupware that Fosters Social Capital Creation: Can Facebook Support Global Virtual Team, Americas Conference on Information Systems, 2009.

[44] L.L. Wu, T.T. Wang, Y.T. Su, M.Y. Yeh, Cultivating Social Capital through Interactivity on Social Network Sites, the Pacific Asia Conference on Information Systems, 2013.

[45] S. Mamonov, The Antecedents and Consequences of Sense of Community on Social Networking Sites, the Americas Conference on Information Systems, 2013.

[46] C. Durst, J. Viol, N. Wickramasinghe, Online Social Networks, Social Capital and Health-Related Behaviors: A State-of-the-art Analysis, Communications of the Association for Information Systems, 32 (2013).

[47] Z. Tufeckci, Gender, Social Capital and Social Network(ing) Sites, the American Sociological Association Annual Meeting, Boston, MA, 2008.

[48] R.M. Kramer, M.B. Brewer, B.A. Hanna, Collective Trust and Collective Action, in: R.M. Kramer, T.R. Tyler (Eds.) Trust in Organizations. Frontiers of Theory and Research, Sage, Thousand Oaks, CA, 1996.

[49] R.J. Lewicki, B.B. Bunker, Developing and Maintaining Trust in Work Relationships, in: R.M. Kramer, T.M. Tyler (Eds.) Trust in Organizations: Frontiers of Theory and Research, Sage, Thousand Oaks, CA, 1996.

[50] D.W. Organ, Organizational Citizenship Behavior, Lexington Books, Lexington, MA, 1988.

[51] B. Misztal, Trust in Modern Societies, Polity Press, Cambridge, UK, 1996.

[52] M. Grayer, I Accepted a Fake Facebook Friend Request, Should I be Afraid?, Naked Security, Sophos Ltd, Burlington, MA, 2011.

[53] J. Edwards, How Facebook Is Hunting Down And Deleting Fake Accounts, Business Insider.com, 2012. 
[54] P.M. Blau, Exchange and Power in Social Life, John Wiley \& Sons, New York, Ny, 1964.

[55] A. Falk, U. Fischbacher, A Theory of Reciprocity, Institute for Empirical Research in Economics, University of Zurich, 2000.

[56] E. Hoffman, K.A. McCabe, V.L. Smith, Behavioral Foundations of Reciprocity: Experimental Economics and Evolutionary Psychology, Economic Inquiry, 36 (1998) 335-352.

[57] S. Faraj, S.L. Johnson, Network Exchange Patterns in Oline Communities, Organization Science, 22 (2011) 1464-1480.

[58] D. Willer, Network Exchange Theory, Praeger, Westport, CT, 1999.

[59] R.C. Mayer, J.H. Davis, F.D. Schoorman, An Integrative Model of Organizational Trust Academy of Management Review, 20 (1995) 709-734.

[60] Y.W. Lee, D.M. Strong, B.K. Kahn, R.Y. Wand, AIMQ, Information \& Management, 40 (2002) 133-146.

[61] M.W. Bovee, Information Quality, University of Kansas, Lawerence, KS, 2004.

[62] A.I. Nicolaou, D.H. McKnight, Perceived Information Quality in Data Exchanges: Effectson Risk, Trust, and Intentions to Use, Information Systems Research, 17 (2006) 332-351.

[63] K. Giffin, The Contribution of Studies of Source Credibility to a Theory of Interpersonal Trust in the Communication Department, Psychological Bulletin, 68 (1967) 104-120.

[64] D. Abrams, M.A. Hogg, Social Identification, Self-Categorization and Social Influence, European Review of Social Psychology, 1 (1990) 195-228.

[65] H.C. Kelman, Compliance, Identification, and Internatilization: Three Processes of Attitude Change, Journal of Conflict Resolution, 2 (1958) 51-60.

[66] D. Cyr, K. Hassanein, M. Head, A. Ivanov, The Role of Social Presence in Establishing Loyalty in E-Service Environments, Interacting with Computers, 19 (2007) 43-56.

[67] D. Schimke, H. Stoeger, A. Ziegler, The Relationship between Social Presence and Group Identification within Online Communities and its Impact on the Success of Online Communities, the 2nd International Conference on Online Communities and Social Computing, Springer-Verlag Berlin Heidelberg, 2007.

[68] K. Neureiter, C. Moser, M. Tscheligi, Look into My Eyes \& See, What You Mean to Me. Social Presence as Source for Social Capital, Lecure Notes in Computing Science2014, pp. 183-198.

[69] J.H. Song, C.R. Hollenbeck, G.M. Zinkhan, The Value of Human Warmth, in: A.Y. Lee, D. Soman (Eds.) Advances in Consumer Research Volume, Association for Consumer Research, Duluth, MN, 2008, pp. 793-794.

[70] P.T. Costa, R.R. McCrae, Revised NEO Personality Inventory (NEO-PI-R) and NEO Five-Factor Inventory (NEO-FFI) manual, Psychological Assessment Resources, Odessa, FL, 1992.

[71] P. Growth, Extraverted Feeling, Personality Growth, 2012.

[72] J.F. Finch, W.G. Graziano, Predicting Depression from Temperament, Personality, and Patterns of Social Relations, Journal of Personality, 69 (2001). 
[73] N. Knoll, S. Burkert, R. Schwarzer, Reciprocal Support Provision: Personality as a Moderator?, European Journal of Personality, 20 (2006) 217-236.

[74] D. Martin, The Strong Silent Type: The Inward Life of the Introvert, University of Illinois, 2010.

[75] D.C. Paulhus, M.N. Bruce, The Effect of Acquaintanceship on the Validity of Personality Impressions, Journal of Personality and Social Psychology, 63 (1992).

[76] R.E. Ready, L.A. Clark, D. Watson, K. Westerhouse, Self and Peer Reported Persaonlity: Agreement, Trait Ratability, and the Self-Based Heuristic, Journal of research in Personality, 34 (2000) 208-224.

[77] D. Watson, B. Hubbard, D. Wiese, Self-Other Agreement in Personality and Affectivity:, Journal of Personality and Social Psychology, 78 (2000) 546-558.

[78] C.L. Hsu, H.P. Lu, Why do People Play On-Line Games?, Information \& Management, 41 (2004) 853-868.

[79] C. Van Slyke, V. Ilie, H. Lou, T. Stafford, Perceived Critical Mass and the Adoption of a Communication Technology, European Journal of Information Systems, 16 (2007) 270-283.

[80] X. Luo, A. Gurung, J.P. Shim, Understanding the Determinants of User Acceptance of Enterprise Instant Messaging, Journal of Organizational Computing and Electronic Commerce, 20 (2010) 155-181.

[81] R.E. Rice, U.E. Gattiker, New Media and Organizational Structuring, in: F. Jablin, L.L. Putnam (Eds.) New Handbook of Organizational Communication, Sage, Newbury Park, CA, 2001, pp. 554-581.

[82] G.S. van Doorn, M. Taborsky, The Evolution of Generalized Reciprocity on Social Interaction Networks, Evolution, 66 (2012) 651-664.

[83] J. Henrich, R. Boyd, S. Bowles, C. Camerer, E. Fehr, H. Gintis, R. McLElreath, In Search of Homo Economicus: Behavioral Experiemnts in 15 Small-Scale Societieis, American Economic Review, 91 (2001) 73. [84] J. Henrich, R. McElreath, A. Barr, J. Ensminger, C. Barrett, A. Bolyanatz, J.C. Cardenas, M. Gurven, E. Gwako, N. Henrich, C. Lesorogol, F. Marlowe, D. Tracer, J. Ziker, Costly Punishment Accross Human Societies, Science, 312 (2006) 1767-1770.

[85] A.H. Eagly, W. Wood, A.B. Diekman, Social Role Theory of Sex Differences and Similarities: A Current Appraisal, in: T. Eckes, H.M. Trautner (Eds.) The Developmental Social Psychology of Gender, Psychology Press, Mahwah, NJ, 2000.

[86] J. Archer, Sex Differenes in Social Behavior: Are the Social Role and Evolutionary Explanations Compatible?, American Psychologist, 51 (1996) 909-917.

[87] R. Su, J. Rounds, P.I. Armstrong, Men and Things, Women and People: A Meta-Analysis of Sex Differences in Interests, Psychological Bulletin, 135 (2009) 859-884.

[88] A.H. Eagly, W. Wood, Explaining Sex Differences in Social Behavior: A Meta-Analytic Perspective, Personality and Social Psychology Bulletin, 17 (1991) 306-315.

[89] M. Clark, M. Ayers, Friendship Similarity during Early Adolescence: Gender and Racial Patterns, Journal of Psychology, 126 (1992) 393-406. 
[90] L.J. Koenig, A.M. Isaacs, J.A.J. Schwartz, Sex Differences in Adolescent Depression and Loneliness: Why are Boys Lonelier if Girls are More Depressed, Journal of Research in Personality, 28 (1994) 27-43.

[91] P.A. Thoits, Stress, Coping, and Social Support Processes: Where Are We? What Next?, Journal of Health and Social Behavior, 35 (1995) 53-79.

[92] D. Belle, Gender Differences in the Social Moderators of Stress, in: R.C. Barnett, L. Biener, G.K. Baruch (Eds.) Gender and Stress, The Free Press, New York, NY, 1987, pp. 257-277.

[93] S.E. Taylor, L.C. Klein, B.P. Kewis, T.L. Gruenewald, R.A.R. Gurung, J.A. Updegraff, Biobehavioral Responses to Stress in Females, Psychological Review, 107 (2000) 411-429.

[94] A. Gunnthorsdottir, K. McCabe, V. Smith, Using the Machiavellianism Instrument to Predict Trustworthiness in a Bargaining Game, Journal of Economic Psychology, 23 (2002) 49.

[95] B. Murray, Boys to Men: Emotional Miseducation, Journal of the American Psychological Assocation, 30 (1999).

[96] M. Kim, WHy Women Volunteer in Korea, Asian Women, 29 (2013) 79-104.

[97] A. Vasalou, A.N. Joinson, D. Courvoisier, Cultural Differences, Experience with Social Networks and the Nature of "True Commitment" in Facebook, International Journal of Human-Computer Studies, 68 (2010) 719728.

[98] N. Park, K.F. Kee, S. Valenzuela, Being Immersed in Social Networking Environment: Facebook Groups, Uses and Gratifications, and Social Outcomes, CyberPsychology \& Behavior, 12 (2009) 729-733.

[99] C.M.K. Cheung, P.Y. Chiu, M.K. Lee, Online Social Networks: Why Do Students Use Facebook?, Computers in Human Behavior, 27 (2011) 1337-1343.

[100] L. Leung, User-Generated Content on the Internet: An Examination of Gratifications, Civic Engagement and Psychological EMpowerment, New Media \& Society, 11 (2009) 1327-1347.

[101] M.H. Nierhoff, Facebook Contry Statistics March 2013, Quintly, Cologne, Germany, 2013.

[102] R. Gu, L.B. Oh, K. Wang, Developing user loyalty for social networking sites: A relational perspective, Journal of Electronic Commerce Research, 17 (2016) 1-21.

[103] Y.-C. Ku, R. Chen, H. Zhang, Why do users continue using social networking sites? An exploratory study of members in the United States and Taiwan, Information \& Management, 50 (2013) 571-581.

[104] J. Henseler, C.M. Ringle, R.R. Sinkovics, The Use of PLS Path Modeling in International Marketing, Advances in International Marketing, 20 (2009) 277-319.

[105] C. Fornell, D. Larcker, Evaluating Structural Equation Models with Unobservable Variables and Measurement Error, Journal of Marketing Research, 18 (1981) 39-50.

[106] J.C. Nunnally, Psychometric Theory, McGraw-Hill, New York, 1976.

[107] D. Gefen, D.W. Straub, M.-C. Boudreau, Structural Equation Modeling and Regression: Guidelines for Research Practice, Communications of the Association for Information Systems, 4 (2000). 
[108] W. Chin, Issues and Opinions on Structural Equation Modeling, MIS Quarterly, 22 (1998) 7-10.

[109] P.M. Podsakoff, S.B. MacKenzie, J.Y. Lee, N.P. Podsakoff, Common Method Biases in Behavioral Research, Journal of Applied Psychology, 88 (2003) 839-903.

[110] L.J. Williams, J.R. Edwards, R.J. Vandenberg, Recent Advances in Causal Modeling Methods for Organizational and Management Research, Journal of Management, 29 (2003) 903-936.

[111] H. Liang, N. Saraf, Q. Hu, y. Xue, Assimilation of Enterprise Systems: The Effect of Institutional Pressures and the Mediating Role of Top Management, MIS Quarterly, 31 (2007) 59-87.

[112] M. Siponen, A. Vance, Neutralization: New Insights Into the Problem of Employee Information Systems Security Policy Violations, MIS Quarterly, 34 (2010) 487-502.

[113] M. Stone, Cross-Validation Choice and Assessment of Statistical Predictions, Journal of the Royal Statistical Society, 36 (1974) 111-133.

[114] S. Geisser, The Predictive Samples Reuse Method with Applications, Journal of American Statistical Association, 70 (1975) 320-328.

[115] W. Chin, The Partial Least Square Approach to Structural Equation Modeling, in: G.A. Marcoulides (Ed.) Modern Methods for Business Research, Lawrence Erlbaum, Mahwah, NJ, 1998, pp. 295-336.

[116] M. Tenenhaus, V.E. Vinzi, Y.M. Chatelin, C. Lauro, PLS Path Modeling, Computational Statistics \& Data Analysis, 48 (2005) 159-205.

[117] J. Cohen, Statistical Power Analysis for the Behavioral Sciences. 2nd edn. Hillsdale, New Jersey: L, Erlbaum, 1988.

[118] J. Cohen, P. Cohen, S.G. West, L.S. Aiken, Applied multiple regression/correlation analysis for the behavioral sciences, Routledge2013.

[119] K.J. Preacher, A.F. Hayes, SPSS and SAS Procedures for Estimating Indirect Effects in Simple Mediation Models, Behavior Research Methods, Instruments, \& Computers, 36 (2004) 717-731.

[120] K.J. Preacher, D.D. Rucker, A.F. Hayes, Addressing Moderated Mediation Hypotheses: Theory, Methods, and Prescriptions, Multivariate Behavioral Research, 42 (2007) 185-227.

[121] X. Zhao, J.G. Lynch, Q. Chen, Reconsidering Baron and Kenny: Myths and truths about mediation analysis, Journal of consumer research, 37 (2010) 197-206.

[122] A.F. Hayes, Beyond Baron and Kenny: Statistical Mediation Analysis in the New Millennium, Communication Monographs, 76 (2009) 408-420.

[123] D.P. MacKinnon, A.J. Fairchild, Current Directions in Mediation Analysis, Current Directions in Psychological Science, 18 (2009) 16-20.

[124] D.P. MacKinnon, C.M. Lockwood, J. Williams, Confidence limits for the indirect effect: Distribution of the product and resampling methods, Multivariate behavioral research, 39 (2004) 99-128.

[125] W.W. Chin, Frequently Asked Questions-Partial Least Squares and PLS-Graph, 2000. 
[126] P.A. Pavlou, O.A. El Sawy, From IT Leveraging Competence to Competitive Advantage in Turbulent Environments, Information Systems Research, 17 (2006) 198-227.

[127] D. Sledgianoski, S. Kulviwat, Social Network Sites: Antecedents of User Adoption and Usage, Americas Conference on Information Systems, 2008.

[128] A. Theotokis, G. Doukidis, When Adoption Brings Addiction: A Use-Diffusion Model for Social Information Systems, International Conference on Information Systems, Phoenix, AZ, 2009.

[129] R. Junco, Comparing Actual and Self-Reported Measures of Facebook Use, computers in Human Behavior, 29 (2013) 626-631.

[130] H. Van der Heijden, User Acceptance of Hedonic Information Systems, MIS Quarterly, 28 (2004) 695-704.

[131] D. Li, P.Y.K. Chau, C.V. Slyke, A Comparative Study of Individual Acceptance of Instant Messaging in the US and China, Communications of the Association for Information Systems, 26 (2010) 85-106.

[132] D. Li, P.Y.K. Chau, H. Lou, Understanding Individual Adoption of Instant Messaging: An Empirical Investigation, Journal of the Association for Information System, 6 (2005) 102-129.

[133] V. McKinney, K. Yoon, F.M. Zahedi, The Measurement of Web-Customer Satisfaction: An Expectation and Disconfirmation Approach Information Systems Research, 13 (2002) 296-315.

[134] H.L. Wu, Utilitarian and Hedonic Values of Social Network Services, Americas Conference on Information Systems, 2009.

[135] V. Venkatesh, M.G. Morris, Why Don't Mean Stop to Ask for Directions? Gender, Social Influence, and Their Role in Technology Acceptance and Usage Behavior, MIS Quarterly, 24 (2000) 115-139.

[136] D. Gefen, D.W. Straub, Consumer Trust in B2C E-Commerce and the Importance of Social Presence, Omega, 32 (2004) 407-424.

[137] D. Gefen, E. Karahanna, D.W. Straub, Inexperience and Experience with Onlien Store: The Importance of TAM and Trust, IEEE Transactions on Engineering Management, 50 (2003) 307-321. 


\section{Appendix A. Measurement Items}

\begin{tabular}{|c|c|c|}
\hline $\begin{array}{c}\text { Principal } \\
\text { Constructs }\end{array}$ & Survey Measurement Items & References \\
\hline $\begin{array}{l}\text { Community } \\
\text { Identification }\end{array}$ & $\begin{array}{l}\text { I feel a sense of belonging towards this social networking site } \\
\text { I have the feeling of togetherness or closeness in this social networking } \\
\text { site } \\
\text { I have a strong attachment towards this social networking site }\end{array}$ & [8] \\
\hline $\begin{array}{l}\text { Perceived } \\
\text { Enjoyment }\end{array}$ & $\begin{array}{l}\text { Enjoyable } \\
\text { Exciting } \\
\text { Pleasant } \\
\text { Interesting } \\
\text { Entertaining }\end{array}$ & {$[130]$} \\
\hline Extroversion & $\begin{array}{l}\text { I enjoy social events } \\
\text { I am outgoing } \\
\text { I like meeting new people }\end{array}$ & {$[131,132]$} \\
\hline $\begin{array}{l}\text { Perceived } \\
\text { Information } \\
\text { Quality }\end{array}$ & $\begin{array}{l}\text { The information shared by members in this social networking site is } \\
\text { accurate } \\
\text { The information shared by members in this social networking site is } \\
\text { complete } \\
\text { The information shared by members in this social networking site is } \\
\text { reliable }\end{array}$ & {$[133]$} \\
\hline $\begin{array}{l}\text { Perceived } \\
\text { Network } \\
\text { Manageability }\end{array}$ & $\begin{array}{l}\text { I can maintain my social networks } \\
\text { I can sustain my relationships with my peers } \\
\text { I can extend my social networks } \\
\text { I can develop new relationships with others }\end{array}$ & {$[134]$} \\
\hline $\begin{array}{l}\text { Perceived } \\
\text { Critical Mass }\end{array}$ & $\begin{array}{l}\text { Many of my buddies use this social networking website } \\
\text { A large percentage of my friends use this social networking website } \\
\text { Many of my friends or family members use this social networking website } \\
\text { frequently }\end{array}$ & {$[131,132]$} \\
\hline $\begin{array}{l}\text { Perceived } \\
\text { Member Trust }\end{array}$ & $\begin{array}{l}\text { Members in this social networking site will not take advantage of the } \\
\text { others even when the opportunity arises. } \\
\text { Members in this social networking site will always keep the promises they }\end{array}$ & {$[8]$} \\
\hline
\end{tabular}




\begin{tabular}{|c|c|c|}
\hline & $\begin{array}{l}\text { make to one another. } \\
\text { Members in this social networking site are truthful in dealing with one } \\
\text { another. } \\
\text { Members in this social networking site will not knowingly do anything bad } \\
\text { to each other }\end{array}$ & \\
\hline $\begin{array}{l}\text { Perceived } \\
\text { Member } \\
\text { Reciprocity }\end{array}$ & $\begin{array}{l}\text { I know that other members in this social networking site will help me if I } \\
\text { need it } \\
\text { I know that other members in this social networking site will share } \\
\text { information with me if I need it } \\
\text { I know that other members in this social networking site will communicate } \\
\text { with me if I need it } \\
\text { I know that other members in this social networking site will interact with } \\
\text { me if I need it }\end{array}$ & {$[8,9]$} \\
\hline Social Influence & $\begin{array}{l}\text { People who are important to me think that I should use this social } \\
\text { networking site } \\
\text { People who influence my behavior think that I should use this social } \\
\text { networking site } \\
\text { People whose opinions I value think that I should use this social } \\
\text { networking site }\end{array}$ & [135] \\
\hline Social Presence & $\begin{array}{l}\text { There is a sense of human contact in this social networking website } \\
\text { There is a sense of personalness in social networking website } \\
\text { There is a sense of human warmth in this social networking website }\end{array}$ & [136] \\
\hline Trust Propensity & $\begin{array}{l}\text { I feel that people are generally trustworthy } \\
\text { I feel that people are generally reliable } \\
\text { I feel that people will not take advantage of me } \\
\text { I usually trust the others }\end{array}$ & [137] \\
\hline $\begin{array}{l}\text { Continued Site } \\
\text { Use }\end{array}$ & $\begin{array}{l}\text { I regularly log in this social networking site } \\
\text { Using this social networking site is part of my daily routine } \\
\text { I access my social networking site frequently }\end{array}$ & {$[127,128]$} \\
\hline
\end{tabular}

\section{Appendix B. Cross Loadings}

\begin{tabular}{|l|c|c|c|c|c|c|c|c|c|c|c|c|c|c|}
\hline & CI & EJ & EX & IQ & LU & NM & CM & MT & PR & SI & SP & TP & SU & AG \\
\hline CI1 & .89 & .44 & .13 & .38 & .03 & .25 & .02 & .38 & .36 & .35 & .43 & .18 & .30 & .03 \\
\hline
\end{tabular}




\begin{tabular}{|c|c|c|c|c|c|c|c|c|c|c|c|c|c|c|}
\hline CI2 & .90 & .47 & .15 & .41 & .01 & .29 & .02 & .41 & .38 & .35 & .44 & .18 & .29 & .00 \\
\hline CI3 & .85 & .45 & .14 & .36 & .05 & .25 & .03 & .33 & .33 & .32 & .37 & .16 & .42 & -.03 \\
\hline EJ1 & .49 & .90 & .22 & .32 & .07 & .48 & .19 & .22 & .40 & .28 & .40 & .16 & .47 & -.02 \\
\hline EJ2 & .52 & .82 & .16 & .38 & .05 & .38 & .05 & .31 & .33 & .19 & .41 & .17 & .34 & -.05 \\
\hline EJ3 & .45 & .88 & .18 & .33 & .05 & .45 & .18 & .22 & .37 & .23 & .39 & .16 & .38 & -.03 \\
\hline EJ3 & .45 & .88 & .22 & .28 & .09 & .46 & .22 & .19 & .42 & .24 & .39 & .17 & .40 & -.04 \\
\hline EJ4 & .39 & .84 & .22 & .22 & .10 & .47 & .25 & .11 & .35 & .20 & .31 & .13 & .43 & -.05 \\
\hline EX1 & .12 & .20 & .84 & .10 & .08 & .23 & .16 & -.01 & .16 & .08 & .12 & .14 & .13 & -.07 \\
\hline EX2 & .16 & .15 & .76 & .16 & .02 & .19 & .05 & .05 & .11 & .05 & .10 & .08 & .07 & -.10 \\
\hline EX3 & .15 & .23 & .91 & .12 & .04 & .29 & .15 & .00 & .20 & .09 & .17 & .19 & .14 & -.09 \\
\hline IQ1 & .39 & .33 & .12 & .92 & -.03 & .19 & -.01 & .39 & .27 & .19 & .29 & .23 & .14 & .04 \\
\hline IQ2 & .40 & .33 & .13 & .91 & .00 & .23 & .01 & .38 & .28 & .19 & .29 & .20 & .14 & -.02 \\
\hline IQ3 & .41 & .31 & .13 & .92 & -.01 & .17 & -.05 & .41 & .27 & .15 & .32 & .20 & .10 & .03 \\
\hline LU & .04 & .09 & .06 & -.02 & 1.00 & .12 & .14 & -.05 & .04 & -.01 & .02 & .03 & .11 & .09 \\
\hline NM1 & .27 & .46 & .22 & .18 & .12 & .89 & .41 & -.01 & .34 & .29 & .34 & .09 & .38 & -.02 \\
\hline NM2 & .26 & .45 & .27 & .16 & .12 & .87 & .41 & .03 & .34 & .30 & .37 & .12 & .33 & -.07 \\
\hline NM3 & .25 & .46 & .25 & .20 & .09 & .87 & .34 & .04 & .35 & .25 & .35 & .12 & .31 & .00 \\
\hline NM4 & .32 & .39 & .26 & .22 & .05 & .76 & .22 & .10 & .31 & .23 & .36 & .11 & .24 & -.10 \\
\hline CM1 & .04 & .18 & .14 & -.03 & .12 & .37 & .93 & -.10 & .20 & .20 & .17 & .01 & .25 & -.07 \\
\hline CM2 & .02 & .18 & .15 & -.03 & .11 & .40 & .95 & -.08 & .21 & .21 & .15 & .02 & .26 & -.06 \\
\hline CM3 & .09 & .21 & .13 & .01 & .15 & .37 & .85 & -.06 & .20 & .22 & .18 & .02 & .26 & .00 \\
\hline MT1 & .37 & .21 & .00 & .34 & -.03 & .07 & -.03 & .84 & .16 & .15 & .21 & .23 & .05 & -.01 \\
\hline MT2 & .36 & .21 & .00 & .39 & -.06 & .02 & -.11 & .92 & .16 & .11 & .18 & .26 & .03 & .00 \\
\hline MT3 & .39 & .22 & .04 & .40 & -.05 & .04 & -.08 & .91 & .20 & .13 & .20 & .30 & .05 & .01 \\
\hline MT4 & .37 & .20 & .01 & .40 & -.05 & .01 & -.10 & .91 & .14 & .12 & .17 & .27 & .03 & .03 \\
\hline PR1 & .44 & .39 & .19 & .29 & .04 & .35 & .15 & .24 & .89 & .28 & .36 & .26 & .26 & .06 \\
\hline PR2 & .34 & .38 & .17 & .24 & .03 & .38 & .20 & .17 & .91 & .26 & .31 & .21 & .23 & .05 \\
\hline PR3 & .36 & .41 & .17 & .28 & .05 & .37 & .24 & .13 & .93 & .28 & .33 & .19 & .25 & .03 \\
\hline PR3 & .35 & .41 & .17 & .27 & .02 & .34 & .22 & .13 & .91 & .26 & .28 & .14 & .22 & .04 \\
\hline SI1 & .34 & .25 & .09 & .16 & -.02 & .31 & .26 & .12 & .29 & .93 & .28 & .11 & .25 & -.05 \\
\hline SI2 & .38 & .25 & .08 & .18 & -.02 & .29 & .20 & .14 & .28 & .95 & .29 & .12 & .25 & -.05 \\
\hline SI3 & .37 & .24 & .09 & .19 & .00 & .29 & .19 & .15 & .28 & .95 & .29 & .12 & .23 & -.08 \\
\hline SP1 & .42 & .39 & .17 & .26 & .05 & .39 & .20 & .14 & .32 & .29 & .88 & .12 & .21 & .02 \\
\hline
\end{tabular}




\begin{tabular}{|c|c|c|c|c|c|c|c|c|c|c|c|c|c|c|}
\hline SP2 & .38 & .39 & .15 & .27 & .03 & .38 & .19 & .12 & .29 & .26 & .87 & .09 & .20 & -.01 \\
\hline SP3 & .42 & .36 & .10 & .32 & -.01 & .31 & .08 & .28 & .31 & .23 & .84 & .18 & .13 & .03 \\
\hline TP1 & .18 & .13 & .14 & .17 & .03 & .11 & .01 & .25 & .17 & .14 & .12 & .89 & .10 & .07 \\
\hline TP2 & .19 & .18 & .18 & .22 & .02 & .12 & .00 & .28 & .18 & .12 & .13 & .90 & .12 & .06 \\
\hline TP3 & .15 & .14 & .12 & .20 & .02 & .09 & .01 & .26 & .18 & .06 & .15 & .80 & .07 & .05 \\
\hline TP4 & .18 & .18 & .16 & .19 & .04 & .13 & .04 & .24 & .24 & .13 & .13 & .87 & .14 & .07 \\
\hline SU1 & .34 & .45 & .16 & .12 & .11 & .36 & .31 & .02 & .25 & .25 & .20 & .13 & .93 & -.07 \\
\hline SU2 & .37 & .44 & .12 & .14 & .09 & .36 & .25 & .04 & .24 & .25 & .20 & .13 & .96 & -.11 \\
\hline SU3 & .38 & .45 & .14 & .13 & .10 & .36 & .25 & .07 & .26 & .23 & .20 & .10 & .95 & -.06 \\
\hline $\mathrm{AG}$ & -.01 & -.04 & -.10 & .02 & .09 & -.05 & -.05 & .01 & .05 & -.06 & .02 & .07 & -.09 & 1.00 \\
\hline
\end{tabular}

CI: Community Identification; EJ: Perceived Enjoyment; EX: Extroversion; IQ: Perceived Information Quality; LU: Length of Site Use; NM: Perceived Network Manageability; CM: Perceived Critical Mass; MT: Perceived Member Trust; PR: Perceived Member Reciprocity; SI: Social Influence: SP: Perceived Social Presence; TP: Trust Propensity: SU: Continued site use; AG: Age 